\title{
A Comprehensive Study for the Laser Cleaning of Corrosion Layers due to Environmental Pollution for Metal Objects of Cultural Value: Preliminary Studies on Artificially Corroded Coupons
}

\author{
A. Siatou, ${ }^{1}$ D. Charalambous, ${ }^{1}$ V. Argyropoulos, ${ }^{1}$ and P. Pouli ${ }^{2}$ \\ ${ }^{1}$ Department of Conservation of Antiquities and Works of Art, Technological Educational Institute of Athens, \\ Ag. Spyridonos str., 12210 Aigaleo, Greece \\ ${ }^{2}$ Institute of Electronic Structure and Lasers, Foundation for Research and Technology-Hellas, P.O. Box 385, \\ Heraklion, 71110 Crete, Greece
}

Received 15 September 2006; Revised 13 December 2006; Accepted 14 December 2006

Recommended by Wolfgang Kautek

\begin{abstract}
This paper is focused on the systematic investigation of the layer-by-layer removal of corrosion products on artificially corroded metal coupons aiming to introduce a methodology for the optimum laser cleaning approach of historical metal objects. Thus, it is very important to determine the chemical composition of the studied surfaces before and after irradiation. A series of laser cleaning studies has been performed on test coupons (reference and artificially corroded). Wavelength and pulse duration effects are investigated. Initial studies were focused on the use of infrared $(1064 \mathrm{~nm})$ and ultraviolet $(355 \mathrm{~nm}$ and $248 \mathrm{~nm})$ radiations of nanosecond ( $n s)$ pulse duration. Damage and removal threshold values were determined for the substrates and the corrosion layers, respectively. The irradiated surfaces are evaluated microscopically under the optical and the scanning electron microscope, while the mineralogical and chemical composition of the various layers is determined with X-ray diffraction and SEM-EDAX analyses, respectively. The results obtained are providing a comprehensive approach for understanding the main mechanisms that are significant in the different laser cleaning regimes, while the optimum cleaning methodologies for the studied materials are being established.
\end{abstract}

Copyright (C 2006 A. Siatou et al. This is an open access article distributed under the Creative Commons Attribution License, which permits unrestricted use, distribution, and reproduction in any medium, provided the original work is properly cited.

\section{INTRODUCTION}

The goal of this work is to find the best method for cleaning iron, copper, and silver alloy historical museum objects, which often require controlled cleaning of the surface from corrosion products without affecting the metal substrate $[1,2]$. These museum objects often have decorative surface details such as engravings, granulation, inlays, gilding, niello, and so forth, but corrosion due to the atmosphere has tarnished or oxidized these surfaces [3]. For museum display, it is often necessary to remove tarnished or oxidized corrosion, while it is important not to affect either the metal substrate (minimal scratching) or the surface decoration. Such controlled mechanical cleaning is difficult with traditional hand or electrically powered tools commonly used by professional conservators-restorers (C-Rs). C-Rs are always in search for optimum methods of cleaning such fine surface detail in a controlled manner. Laser cleaning is able to provide an adequate cleaning of historical objects.

Nowadays lasers are used widely in analysis, monitoring, and conservation of cultural heritage objects (see [4]). Their unique properties are being responsible for high control, selectivity, minimal contact, and versatility; attributes that are essential for any conservation intervention on such valuable objects. In metal conservation, there have been plenty of studies aiming to use lasers for the removal of different corrosion layers, encrustations, and coatings from various metal surfaces with mixed results (see [5-8]). Still many issues are not yet resolved and thus the application of lasers in metal conservation is not universally accepted. Such issues include the preservation of the original surface, the understanding of the formation of unwanted laser-induced alteration layers, the final morphology of the irradiated surfaces, and the establishment of a methodology for the everyday 
TABLE 1: The composition of the reference samples and the artificial corrosion layers.

\begin{tabular}{|c|c|c|c|c|}
\hline \multicolumn{2}{|c|}{ Reference samples } & \multicolumn{2}{|c|}{ Artificially corroded layers } & \multirow[b]{2}{*}{ Description } \\
\hline Type of metal & Composition (\%) & Corrosion products & Color & \\
\hline Iron alloy & $\begin{array}{c}\text { Fe: } 97.84 \pm 0.15 \\
\text { C: } 0.81 \pm 0.14 \\
\text { Mn: } 1.25 \pm 0.04 \\
\text { Cr: } 0.09 \pm 0.03 \\
\end{array}$ & $\begin{array}{l}\text { Goethite, } \alpha \text { - } \mathrm{FeO}(\mathrm{OH}) \\
\text { and/or akageneite, } \\
\beta \text { - } \mathrm{FeO}(\mathrm{OH})\end{array}$ & Yellow-brown & $\begin{array}{l}\text { Dark brown to orange } \\
\text { corrosion spots evenly } \\
\text { distributed on the surface }\end{array}$ \\
\hline \multirow[t]{2}{*}{ Copper alloy } & $\begin{array}{c}\text { Cu: } 84.52 \pm 0.75 \\
\text { Zn: } 5.69 \pm 0.21 \\
\text { Pb: } 4.83 \pm 0.54 \\
\text { Sn: } 4.87 \pm 0.25\end{array}$ & $\begin{array}{l}\text { Copper(II)hydroxide } \\
\text { nitrate, } \mathrm{Cu}_{2} \mathrm{NO}_{3}(\mathrm{OH})_{3}\end{array}$ & Green & Uniform green corrosion layer \\
\hline & $\begin{array}{l}\text { (trace elements-average: } \\
0.004 \mathrm{Mn}, 0.056 \mathrm{Fe} \\
0.06 \mathrm{Ni}, 0.002 \mathrm{Si} \text { ) }\end{array}$ & Copper(II)oxide, $\mathrm{CuO}$ (cuprite) & Black & $\begin{array}{l}\text { At some places, a black or } \\
\text { dark brown layer of oxide } \\
\text { is visible underneath the } \\
\text { green corrosion }\end{array}$ \\
\hline Silver alloy & $\begin{array}{l}\text { Ag: } 95.62 \pm 0.15 \\
\text { Cu: } 4.19 \pm 0.14 \\
\text { Mg: } 0.19 \pm 0.07\end{array}$ & Silver(II)sulphide, $\mathrm{Ag}_{2} \mathrm{~S}$ & Black & $\begin{array}{l}\text { Tarnishing (uniform } \\
\text { black corrosion product } \\
\text { at the entire surface) }\end{array}$ \\
\hline
\end{tabular}

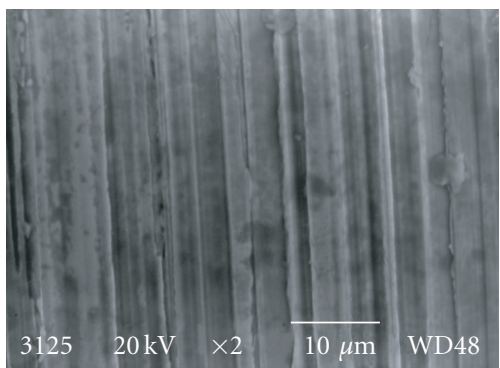

(a)

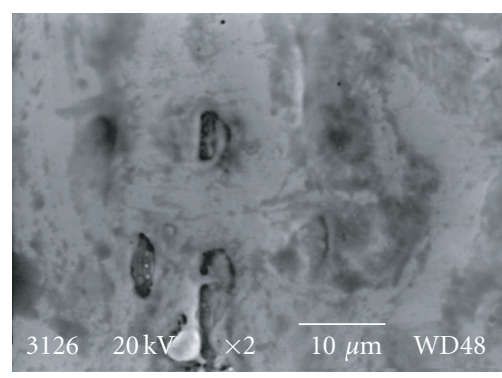

(b)

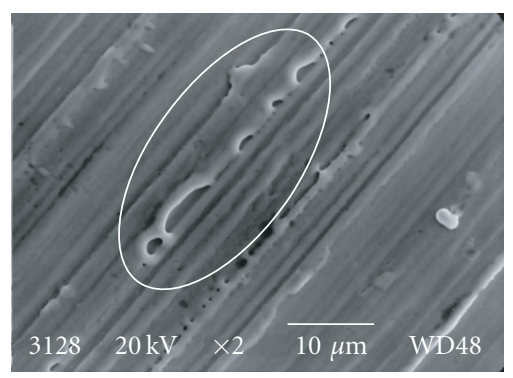

(c)

FIgURE 1: Determination of the damage threshold with Nd:YAG laser pulses at $1064 \mathrm{~nm}$ on iron reference sample. At high fluences $\left(5.7 \mathrm{~J} / \mathrm{cm}^{2}\right)$, the grinding lines of the reference surface are completely destroyed (melted), while at the damage threshold $\left(0.9 \mathrm{~J} / \mathrm{cm}^{2}\right) \mathrm{melting}$ is limited and occurs only at the edges of the grinding lines. SEM photos under 2000 magnification, scale marker length: $10 \mu \mathrm{m}$.

implementation of laser cleaning in the conservation practice.

The above studies have been mainly investigating the effects that the radiation of various laser systems at different wavelengths with nanosecond $(n s)$ pulse duration may cause. Recently, the use of ultrashort laser pulses to clean metal surfaces was reported with very interesting results [9]. Such lasers may be a viable solution to many of the above mentioned unclear issues in metal conservation as they offer unique advantages in comparison to the ns laser systems; such as minimal thermally and chemically induced alterations, higher spatial confinement, control, and so forth [10].

\section{EXPERIMENT}

This work aims to investigate in a systematic way how the wavelength and pulse duration may affect the laser-assisted removal of various corrosion layers formed on historical metal objects exposed to urban environment. Artificially corroded samples of iron, copper, and silver alloys are being used for the evaluation of the different laser cleaning regimes and methodologies. Damage and removal threshold values are determined both for the metal substrate and the corrosion layers, while physicochemical analysis on the irradiated surfaces aims to detect any laser-induced alterations. The specific objective is to determine the fluence values adequate to remove corrosion products from the different metal substrates, in a controlled manner, without altering the object's original surface or damaging the metal substrate.

The project's plan includes the study of both infrared $(1064 \mathrm{~nm})$ and ultraviolet $(355 \mathrm{~nm}$ and $248 \mathrm{~nm})$ laser radiations at various pulse durations (microsecond, $\mu$ s, nanosecond, $n s$, and picosecond, $p s$ ). The initial results presented herein were focused on the study of all the wavelengths $(1064 \mathrm{~nm}, 355 \mathrm{~nm}$, and $248 \mathrm{~nm})$ in the $n s$ regime. 


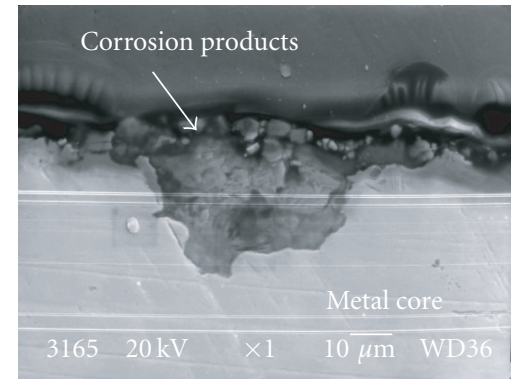

(a)

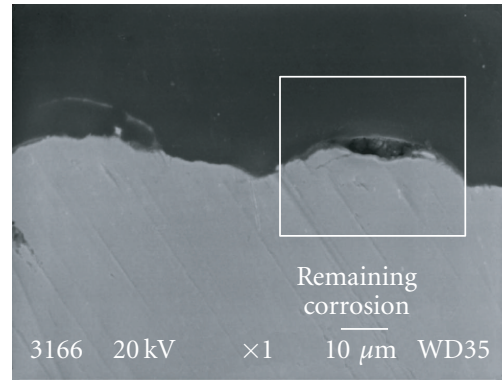

(b)

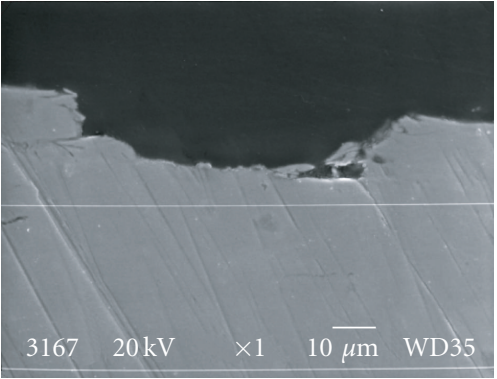

(c)

FIGURE 2: Cross-sections of the artificially corroded iron sample: (a) the corrosion products are formed both inwards and outwards the metal core, (b) mechanical cleaning may leave traces of corrosion, and (c) laser cleaning at the determined ablation threshold $\left(0.4 \mathrm{~J} / \mathrm{cm}^{2}\right)$ removes efficiently all the corrosion without affecting the metal substrate. SEM photos under 2000 magnification, scale marker length: $10 \mu \mathrm{m}$.

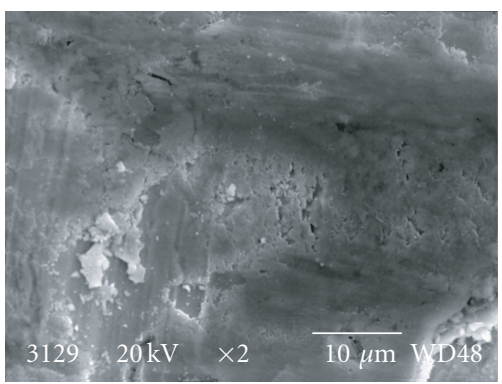

(a)

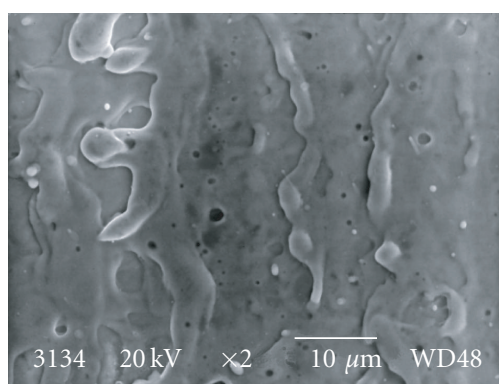

(b)

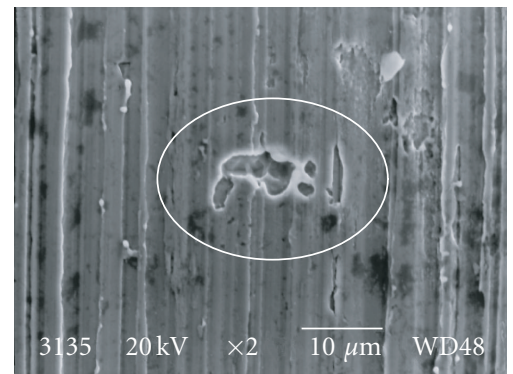

(c)

FIGURE 3: Determination of the ablation threshold with Nd:YAG laser pulses at $1064 \mathrm{~nm}$ on artificial corrosion on iron (a). At high fluences $\left(5.7 \mathrm{~J} / \mathrm{cm}^{2}\right)$, the grinding lines of the reference surface are completely destroyed (melted) (b), while at the damage threshold $\left(0.4 \mathrm{~J} / \mathrm{cm}^{2}\right)$ melting is limited (c) and the corrosion is efficiently removed. SEM photos under 2000 magnification, scale marker length: $10 \mu \mathrm{m}$.

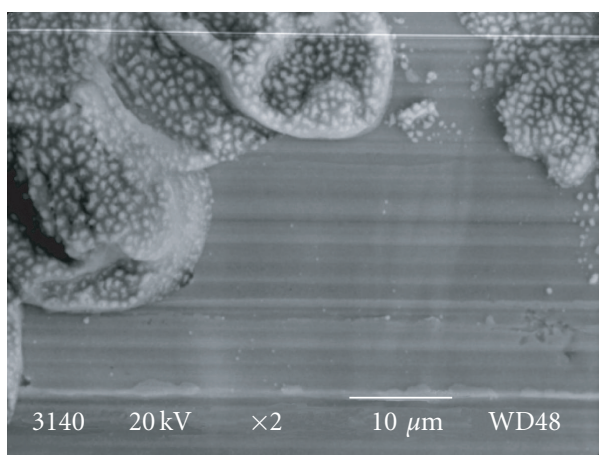

Figure 4: Ultraviolet pulses ( $\mathrm{KrF}$ excimer laser at $248 \mathrm{~nm}$ ) could not remove the corrosion layer, while further alteration of the corroded surfaces occurs. SEM photos under 2000 magnification, scale marker length: $10 \mu \mathrm{m}$.

Due to the nature of the studied corrosion layers (pulverant and/or randomly distributed corrosion spots) and substrates (metal surfaces) it was not possible to establish in a systematic way the amount of ablated material per pulse for a series of different fluence values and thus determine from the corresponding graph the ablation threshold for each studied material [11]. Instead, the determination of the damage threshold on the metal substrate and the ablation threshold of the artificial corrosion layer was based on the presence of any melting or discoloration feature observed on the studied surface upon its irradiation with a single laser pulse as a function of increasing fluence values. Figure 1 shows a series of SEM photos indicating the determination process of the damage threshold on reference iron coupon. The grinding lines of the reference surface (see Figure 1(a)) are completely destroyed upon irradiation with $\mathrm{Nd}$ :YAG laser pulses at $1064 \mathrm{~nm}$ at relatively high fluence values $\left(5.7 \mathrm{~J} / \mathrm{cm}^{2}\right)$, where intense melting occurs. Instead, at $0.9 \mathrm{~J} / \mathrm{cm}^{2}$, melting is limited and observed only at the edges of the grinding lines, and thus this fluence value is considered as the ablation threshold of the iron core metal.

\section{MATERIALS AND METHODS}

\subsection{Samples}

Test samples representing the composition and the corrosion of historical metal artifacts were prepared. The three types of metal substrates studied were (a) iron (low carbon steel), (b) 
TABLE 2: The humid-dry cycles used to create corrosion on iron.

\begin{tabular}{c|c|c}
\hline Time (hours) & Temperature $\left({ }^{\circ} \mathrm{C}\right)$ & Relative humidity $(\%)$ \\
\hline 24 & 30 & 100 \\
24 & Variable 25-30 & Variable 50-60 \\
24 & 30 & 100 \\
\hline
\end{tabular}

TABLE 3: The parameters of the employed laser systems.

\begin{tabular}{l|c|c|c}
\hline Laser system & Type & Wavelength $(\mathrm{nm})$ & Pulse duration \\
\hline BMI series 5022 DNS 10 & Q-switched Nd:YAG & 1064 & $5-7 \mathrm{~ns}$ \\
& & 355 & $5-7 \mathrm{~ns}$ \\
TUI model Braggstar 200 & KrF excimer & 248 & $10 \mathrm{~ns}$ \\
\hline
\end{tabular}

copper (cast bronze), and (c) $950^{\circ}$ silver alloys. The detailed information on the composition of the reference surfaces is presented in Table 1.

Artificial corrosion was then produced on the metal surface using the following different methodologies according to the substrate:

(A) iron alloy coupons were corroded in a "voetsch industrietechnik (VC 4034)" climatic chamber using humid-dry cycles. The methodology used was based on the artificial corrosion of similar coupons prepared by Heritage Malta ${ }^{1}$ and are given in Table 2. This type of artificial corrosion creates localized corrosion spots randomly distributed on the iron surface;

(B) bronze coupons were corroded by direct application on the surface of a $\mathrm{Cu}\left(\mathrm{NO}_{3}\right)_{2}+\mathrm{NH}_{4} \mathrm{OH}$ solution, as suggested in [12]. A cold solution of $\mathrm{Cu}\left(\mathrm{NO}_{3}\right)_{2}+\mathrm{NH}_{4} \mathrm{OH}$ was applied by brushing directly onto the heated metal surface at several time intervals. The bronze coupons were then dried in room condition. The corroded surface is uniformly covered with a layer of green corrosion products (copper(II)hydroxide nitrate);

(C) silver exposed to urban or indoor environment, as most historical objects are, tarnishes due to the sulfur containing atmosphere, forming a black layer of silver sulfide on the objects surface $[3,13]$. For the artificial corrosion of silver, we created an atmosphere containing sulfur ions in a closed chamber by acidifying sodium sulfide $\left(\mathrm{Na}_{2} \mathrm{~S}\right)$. After one-day exposure, an evenly distributed black layer was created on the silver surface.

The aim is the total removal of the corrosion products on iron and silver and the removal of the green corrosion layer on bronze, without any alteration (both in color and surface morphology) to the underlying metal surface.

\footnotetext{
${ }^{1}$ Heritage Malta (HM), Old Royal Naval Hospital, Bighi,CSP 12, Kalkara, Malta.
}

\subsection{Laser irradiation}

Irradiation studies were carried out using the following laser systems:

(i) A modified Q-switched Nd:YAG laser (BMI, series 5022 DNS 10) with pulse duration in the range of $5-7 \mathrm{~ns}$ and maximum repetition rate of $10 \mathrm{~Hz}$. The system emits both the fundamental wavelength (at $1064 \mathrm{~nm}$ ) and its third harmonic (at $355 \mathrm{~nm}$ ) at maximum energy outputs of $1000 \mathrm{~mJ}$ and $300 \mathrm{~mJ}$, respectively.

(ii) A compact excimer laser (TUI laser, Braggstar 200 model) operating at $248 \mathrm{~nm}(\mathrm{KrF})$. The system produces pulses (10 ns) with maximum energy of $16 \mathrm{~mJ}$.

All laser beams were focused by means of a fused silica planoconvex lens ( $f=+100 \mathrm{~mm}$ ) on the sample surface. Optical attenuators introduced in the beam path in various angles were employed to adjust the energy output of each laser beam. The parameters of the employed systems are presented in Table 3.

The complementary application of wetting solutions (water and/or ethanol) was also considered. As there was no obvious difference in the behavior of the two wetting agents, ethanol was chosen because it is inert with the metal surface while water may cause further corrosion to the metal, that is, flash rusting on iron. Its application on the corroded bronze samples was found to enhance the cleaning process and remove the corrosion products in a homogeneous way without discoloration phenomena. On the other hand, no obvious difference was observed on iron samples while it was believed to cause the formation of bluish coloration on the surface of silver.

\subsection{Analytical techniques}

The surface morphology of the irradiated samples was studied using a stereomicroscope (SM), while specially prepared samples embedded in resin which were examined under reflected polarized light by means of a Nikon ECLIPSE ME 
TABLE 4: Laser cleaning tests on iron.

\begin{tabular}{|c|c|c|c|c|}
\hline Laser system & Wavelength $\lambda(\mathrm{nm})$ & $\begin{array}{l}\text { Damage threshold for the } \\
\text { metal substrate }\left(\mathrm{J} / \mathrm{cm}^{2}\right)\end{array}$ & $\begin{array}{l}\text { Ablation threshold for the } \\
\text { corrosion products }\left(\mathrm{J} / \mathrm{cm}^{2}\right)\end{array}$ & Comments \\
\hline Nd:YAG & 1064 & 0.90 & 0.35 & $\begin{array}{l}\text { Suggested cleaning } \\
\text { at } 0.6-0.8 \mathrm{~J} / \mathrm{cm}^{2}\end{array}$ \\
\hline Nd:YAG & 355 & 0.4 & 0.2 & \multirow{2}{*}{$\begin{array}{l}\text { The corrosion products are altered } \\
\text { when many pulses are applied }\end{array}$} \\
\hline KrF excimer & 248 & \multicolumn{2}{|c|}{$\begin{array}{l}\text { The metal is not affected at the } \\
\text { studied fluences }\left(0.1-0.5 \mathrm{~J} / \mathrm{cm}^{2}\right)\end{array}$} & \\
\hline
\end{tabular}

TABLE 5: Laser cleaning tests on copper.

\begin{tabular}{|c|c|c|c|c|}
\hline Laser system & Wavelength $\lambda(\mathrm{nm})$ & $\begin{array}{l}\text { Damage threshold for the } \\
\text { metal substrate }\left(\mathrm{J} / \mathrm{cm}^{2}\right)\end{array}$ & $\begin{array}{l}\text { Ablation threshold for the } \\
\text { green corrosion layer }\left(\mathrm{J} / \mathrm{cm}^{2}\right)\end{array}$ & Comments \\
\hline Nd:YAG & 1064 & 0.4 & $0.3-0.4$ & $\begin{array}{l}\text { Suggested cleaning } \\
\text { at } 0.3 \mathrm{~J} / \mathrm{cm}^{2}\end{array}$ \\
\hline Nd:YAG & 355 & 0.2 & 0.2 & \\
\hline KrF excimer & 248 & \multicolumn{2}{|c|}{$\begin{array}{l}\text { The metal is not affected at the } \\
\text { studied fluences }\left(0.1-0.5 \mathrm{~J} / \mathrm{cm}^{2}\right)\end{array}$} & of corrosion products \\
\hline
\end{tabular}

600 microscope (OM) equipped with a HITACHI KP-CS 71 digital camera. The cross-sections were studied in various magnifications $(5 x, 10 x, 20 x)$ aiming to determine the interface between the corrosion layer and the authentic surface and thus deciding the cleaning limit. A JEOL JSM-840 scanning electron microscope (SEM) was employed to study any laser induced alterations to the original surface.

$\mathrm{X}$-ray diffraction analysis (XRD) was used to identify the chemical composition of the various corrosion layers as well as possible changes in the chemistry of the irradiated surfaces. Analysis was performed by a RIGAKU, RINT 2000 series powder diffractometer, using $\mathrm{Cu} \mathrm{Kal}$ radiation $(1,5405 \AA)$. Measurements were carried out in the range $3^{\circ}<$ $2<70^{\circ}$ with a step of $0.02^{\circ}$.

\section{RESULTS AND DISCUSSION}

\subsection{Iron}

Figure 2 shows a series of cross-sections on artificially corroded iron: Figure 2(a) shows the formation of corrosion spots both inwards and outwards the original surface, Figure 2(b) shows their insufficient removal by mechanical means (traces of corrosion products are still left on the surface), and Figure 2(c) shows their total removal by laser application (there are no traces of corrosion products left).

The results of the irradiation tests are summarized in Table 4. The Q-switched Nd:YAG laser system emitting pulses of ns pulse duration at $1064 \mathrm{~nm}$ was found to be able to remove corrosion products of iron in-depth without affecting the metal core. The selection of the ablation threshold on the corrosion is presented in Figure 3.

On the opposite, ultraviolet radiation both at $355 \mathrm{~nm}$ and $248 \mathrm{~nm}$ was insufficient to remove the corrosion spots while causing further alteration (blackening) (see Figure 4). The chemistry of the blackened surfaces is under investigation.

\subsection{Bronze}

Two distinctive corrosion layers are observed on the bronze coupons: a thick green corrosion layer $\left(\mathrm{Cu}_{2} \mathrm{NO}_{3}(\mathrm{OH})_{3}\right)$ that uniformly covers the entire surface (Figure 5(a)) and under this a dark oxide layer $(\mathrm{CuO})$. Considering that this dark oxide layer acts as a barrier that protects the underlying metal surface from further corrosion [1] it was decided to remove only the green corrosion layer while keeping the oxide layer intact.

The results of the irradiation tests are summarized in Table 5. Similarly to the iron case, the infrared radiation at $1064 \mathrm{~nm}$ emitted from the Nd:YAG laser at fluences in the range of $0.3-0.4 \mathrm{~J} / \mathrm{cm}^{2}$ was able to efficiently remove the green corrosion layer without any alteration to the underlying oxide layer (see Figure 5(b)). It was also shown that the application of a thin layer of ethanol enhances the cleaning process.

On the other hand, irradiation tests with ultraviolet wavelengths resulted in an apparent discoloration (towards yellow) of the green corrosion layer (see Figure 5(c)). The chemistry of the yellow-discolored layers is under investigation.

\subsection{Silver}

The silver sulfide $\left(\mathrm{Ag}_{2} \mathrm{~S}\right)$ layer formed on the coupons surface is very adherent and thus difficult to remove. Our aim is to reach the original surface and expose the shining silver surface. However, this task is difficult since silver is very sensitive to laser irradiation causing melting on the surface with all wavelengths. 
TABLE 6: Laser cleaning tests on silver.

\begin{tabular}{lcccc}
\hline Laser system & Wavelength $\lambda(\mathrm{nm})$ & $\begin{array}{l}\text { Damage threshold for the } \\
\text { metal substrate }\left(\mathrm{J} / \mathrm{cm}^{2}\right)\end{array}$ & $\begin{array}{l}\text { Ablation threshold for the } \\
\text { corrosion layer }\left(\mathrm{J} / \mathrm{cm}^{2}\right)\end{array}$ & Comments \\
\hline Nd:YAG & 1064 & 1.5 & 0.20 & $\begin{array}{l}\text { Melting of the corroded metal } \\
\text { occurs even at } 0.1 \mathrm{~J} / \mathrm{cm}^{2}\end{array}$ \\
\hline Nd:YAG & 355 & 0.55 & $\begin{array}{l}\text { Removal of a superficial } \\
\text { corrosion layer, discoloration } \\
\text { (whitening) of the surface }\end{array}$ \\
\hline KrF excimer & 248 & $\begin{array}{l}\text { The metal is not affected } \\
\text { at the studied fluences } \\
0.1-0.5 \mathrm{~J} / \mathrm{cm}^{2}\end{array}$ & 0.25 & $\begin{array}{l}\text { Removal of a superficial } \\
\text { corrosion layer without any } \\
\text { damage to the substrate }\end{array}$ \\
\hline
\end{tabular}

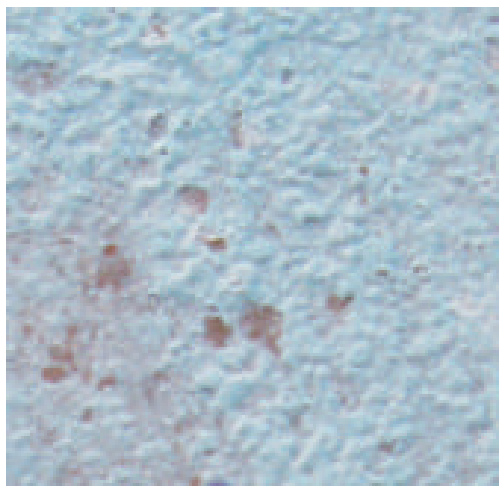

(a)

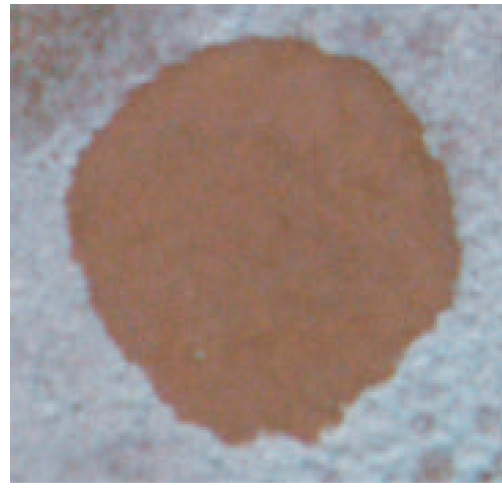

(b)

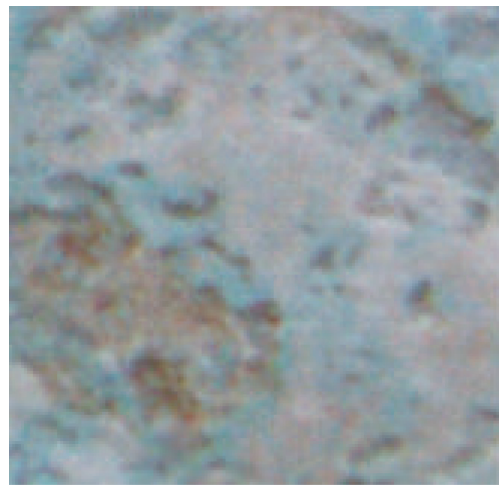

(c)

FIGURE 5: (a) Uniform formation of green corrosion products on bronze samples, (b) removal of the green corrosion layer at $1064 \mathrm{~nm}$, fluence value equal to the threshold $\left(0.3 \mathrm{~J} / \mathrm{cm}^{2}\right)$, (c) discoloration (yellowing) of the green corrosion product at $355 \mathrm{~nm}\left(0.2 \mathrm{~J} / \mathrm{cm}^{2}\right)$. Horizontal dimension: $5 \mathrm{~mm}$.

The best case scenario is the removal of a superficial corrosion layer using UV irradiation. This can be achieved with a KrF excimer laser emitting pulses of $n s$ duration at $248 \mathrm{~nm}$, since at $355 \mathrm{~nm}$ whitening appears on the surface and the metal becomes dull. The results of the irradiation tests on the silver samples are presented in Table 6.

\subsection{Overall comments/discussion}

From the above-shown preliminary results, focused on the study of infrared and ultraviolet wavelengths $(1064 \mathrm{~nm}$, $355 \mathrm{~nm}$, and $248 \mathrm{~nm}$ ) in the $n s$ regime, it is clear that many issues still have to be answered. Infrared radiation at $1064 \mathrm{~nm}$ with $n s$ pulse duration emitted from a Q-switched Nd:YAG laser was found to be able to remove artificially grown corrosion spots on iron and relatively thin corrosion products from bronze coupons with quite satisfactory results. Still their application in real objects with thicker, harder, and more inhomogeneous corrosion layers should be considered. Similarly, ultraviolet laser pulses at $248 \mathrm{~nm}$ emitted from a $\mathrm{KrF}$ excimer laser were found to be able to remove tarnish from silver quite satisfactory, still the final surface lacks its initial glossy appearance. Studies are now performed with laser systems with shorter pulse widths and the initial results are very satisfactory. The thorough and comparative evaluation of these studies may answer many of the unsolved issues in metal conservation and will indicate the appropriate laser parameters for the cleaning of each individual problem.

\section{ACKNOWLEDGMENTS}

This project was funded by the European Social Fund and National Resources-(EPEAEK II) ARCHIMEDES, entitled "The application of new technologies for the cleaning of archaeological and historical metal objects; investigation of the possibility of applying laser technology and electrolytic methods." The authors would like to thank the Greek Center

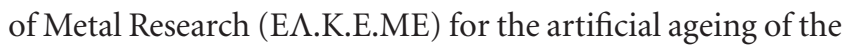
iron alloy coupons.

\section{REFERENCES}

[1] J. M. Cronyn, The Elements of Archaeological Conservation, Routledge, Taylor and Francis, London, UK, 1990, edition 2001.

[2] R. Bertholon and C. Relier, "Les métaux archéologiques," in La conservation en archéologie. Méthodes et pratique de la 
conservation-restauration des vestiges archéologiques, Masson, Paris, France, 1990.

[3] L. Selwyn, Metals and Corrosion: A Handbook for the Conservation Professionals, Canadian Conservation Institute, Ottawa, Canada, 2004.

[4] C. Fotakis, D. Anglos, V. Zafiropulos, S. Georgiou, and V. Tornari, Lasers in the Preservation of Cultural Heritage: Principles and Applications, Edited by R. G. W. Brown and E. R. Pike, Taylor and Francis, New York, NY, USA, 2006.

[5] C. A. Cottam and D. C. Emmony, "TEA-CO $\mathrm{CO}_{2}$ laser surface processing of corroded metals," Corrosion Science, vol. 41, no. 8, pp. 1529-1538, 1999.

[6] P. Mottner, G. Wiedemann, G. Haber, W. Conrad, and A. Gervais, "Laser cleaning of metal surface-laboratory investigations," in Proceedings of the International Conference LACONA V Lasers in the Conservation of Artworks, vol. 100 of Springer Proceedings in Physics, pp. 79-86, Osnabrueck, Germany, September 2005.

[7] Y. Koh and I. Sárady, "Cleaning of corroded iron artefacts using pulsed TEA $\mathrm{CO}_{2}$ - and Nd:YAG-lasers," Journal of Cultural Heritage, vol. 4, supplement 1, pp. 129-133, 2003.

[8] R. Pini, S. Siano, R. Salimbeni, M. Pasquinucci, and M. Miccio, "Tests of laser cleaning on archeological metal artefacts," Journal of Cultural Heritage, vol. 1, supplement 1, pp. S129-S137, 2000.

[9] T. Burmester, M. Meier, H. Haferkamp, S. Barcikowski, J. Bunte, and A. Ostendorf, "Femtosecond laser cleaning of metallic cultural heritage and antique works," in Proceedings of the International Conference LACONA V Lasers in the Conservation of Artworks, vol. 100 of Springer Proceedings in Physics, pp. 61-69, Osnabrueck, Germany, September 2005.

[10] D. Bäuerle, Laser Processing and Chemistry, Springer, Berlin, Germany, 2000.

[11] S. Georgiou, "Overview of laser processing and cleaning methods," in Lasers in the Preservation of Cultural Heritage: Principles and Applications, chapter 6, Taylor and Francis, New York, NY, USA, 2006.

[12] R. Hughes and M. Rowe, The Colouring Bronzing and Patination of Metals, Thames and Hudson, London, UK, 1991.

[13] I. Singh, P. Sabita, and V. A. Altekar, "Silver tarnishing and its prevention-a review," Anti-Corrosion Methods and Materials, vol. 30, no. 7, pp. 4-8, 1983. 